\title{
WILLINGNESS AND PARTICIPATION TOWARD PREVENTION OF MOTHER TO CHILD TRANSMISSION AMONG MALES OF REPRODUCTIVE AGE. A STUDY FROM KILIMANJARO-TANZANIA.
}

\author{
By: Yohana Boniphace (MD5 MUHAS-2008/2009)
}

\begin{abstract}
OBJECTIVE

To determine willingness and participation toward Prevention of Mother to Child Transmission (PMTCT) among males of Reproductive age in Hedaru Ward at Same district; Kilimanjaro region.
\end{abstract}

\section{METHODOLOGY}

A descriptive cross sectional study was conducted among 138 randomly sampled males of reproductive age at Hedaru Ward in Same District using a semi-structured questionnaire with both closed and open ended questions.

\section{RESULTS}

The result showed that of the 138 respondents, 103(74.6\%) were not willing to participate in PMTCT programs by accompanying their couples to the Antenatal Clinics. Also majority of them (61.4\%) have never participated in PMTCT programs in Antenatal Clinics. The reasons for poor involvement of males in PMTCT programs were; being busy [25.2\%], cultural reasons[21.4\%], lack of knowledge on the importance of the programs (21.4\%).

\section{CONCLUSION}

Most males do not participate in PMTCT programs because they don't realise their importance due to inadequate knowledge about the programs, while others are hindered by cultural settings in the community which pose negative perceptions toward the programs.

\section{RECOMMENDATIONS}

PMTCT clinics should be made men friendly and service providers should ensure that all efforts are made to involve men from the beginning in every PMTCT intervention. Men should be enforced to accompany their couples to the ANC through denying maternal services to the mother unless she comes with her husband/ partner.

\section{INTRODUCTION}

Since the beginning of HIV epidemic it is estimated that nearly 5 million children are currently living with HIV/AIDS, most of them born to HIV positive mothers having acquired the virus before birth, during labour and delivery and/or through breast feeding. ${ }^{1}$

It is estimated that $\mathbf{3 8 . 6}$ million people worldwide were living with HIV by the end of 2005. It is also estimated that 4.1 million became newly infected with
HIV currently and 2.8 million lost their lives to AIDS by 2005. Africa remains the global epicentre of the AIDS pandemic where by Sub Saharan Africa carries the largest burden. However the epidemic in this region is extremely severe in Eastern and Southern Africa. It is also estimated that one in every three pregnant women attending public antenatal clinics were having HIV infection by 2004 . $^{2}$

In Tanzania about $12 \%$ of pregnant women attending antenatal clinics are living with HIV and in 2005, 
around 700,000 children under 15 years were infected with HIV, mainly through MTCT. About $90 \%$ of these MTCT infections occurred in Sub-Saharan Africa. Hence PMTCT programmes are central rallying point for enhanced treatment, care and support services for women, their children and families. ${ }^{2}$

Despite achievement of PMTCT-high acceptance rate of $85 \%$, a number of challenges have been identified to affect the effectiveness of the program; these include poor male partner involvement, low uptake of ARV prophylaxis, and poor community participation and support. ${ }^{3}$

Men's willingness and participation may mean many things depending on the couple and community. A study done in Ivory Cost pointed out that fear of male partner's had a negative effect on the uptake of PMTCT interventions among HIV infected women. Unmarried female accepted the PMTCT package more frequently than those who had a male partner ${ }^{4}$

Again, another study was done in Uganda on the barriers to the implementation of the programs for the prevention of maternal to child transmission of HIV where by 404 women at large urban hospital and 3 rural clinics that had recently started implementing PMTCT were interviewed. From the discussion it was observed that the strongest predictor of willingness to accept an HIV test was the woman's that her husband would approve of her testing for HIV. ${ }^{5}$

Lack of MTCT knowledge among men is a barrier to their participation in PMTCT and hence $\mathrm{MCH}$ care, as shown in a study to identify factors that influence male participation among community members in Dodoma, Tanga, and Kilimanjaro (Burke, 2004). Similar findings were found in a study done in Majengo health centre. The study sought to asses male participation on the ongoing PMTCT and to describe reasons for failure to participate as perceived by men. ${ }^{6}$

\section{METHODOLOGY}

A descriptive cross sectional study was conducted among 138 randomly sampled males of reproductive age at Hedaru Ward in Same District using a semistructured questionnaire with both closed and open ended questions. Data processing and analysis was done through the EPI- Info computer software. Ethical clearance approval and permission to undertake the study was obtained from Muhimbili University of Health and Allied Sciences (MUHAS) and from District Executive Director of Same district. Informed consent from the participants was obtained before administering the questionnaires and they were assured of anonymous and freedom to participate in the study.

\section{RESULTS}

Table1: Distribution on willingness of males to participate in PMTCT programs at the Antenatal Clinics.

\begin{tabular}{|l|l|l|}
\hline Response & Frequency & Percent \\
\hline Yes & 35 & $25.4 \%$ \\
\hline No & 103 & $74.6 \%$ \\
\hline Total & 138 & $100.0 \%$ \\
\hline
\end{tabular}

Among 138 respondents, 103(74.6\%) were not willing to participate in PMTCT programs by accompanying their couples to the Antenatal Clinics.

Table 2: Distribution of males' participation in PMTCT programs at the Antenatal Clinics.

\begin{tabular}{|l|l|l|}
\hline Response & Frequency & Percent \\
\hline Yes & 53 & $38.4 \%$ \\
\hline No & 85 & $61.6 \%$ \\
\hline Total & 138 & $100.0 \%$ \\
\hline
\end{tabular}

Majority of them (61.6\%) have never participated in PMTCT programs at Antenatal Clinics.

Table 3: Distribution on the reasons for males' participation in PMCTCT program.

\begin{tabular}{|l|l|l|}
\hline Response & Frequency & Percent \\
\hline Love to their wives & 15 & $42.9 \%$ \\
\hline Health education & 17 & $48.6 \%$ \\
\hline Distance & 3 & $8.6 \%$ \\
\hline Total & 35 & $100.0 \%$ \\
\hline
\end{tabular}

Among those who participated in PMTCT programs 35(25.4\%), 17 (48.6\%) needed health education and 15 (42.9\%) were driven by love for their wives.

Table 4: Distribution of factors hindering males' participation in PMTCT program at the Antenatal Clinics 


\begin{tabular}{|l|l|l|}
\hline Response & Frequency & Percent \\
\hline $\begin{array}{l}\text { Women affairs / } \\
\text { responsibility }\end{array}$ & 16 & $15.5 \%$ \\
\hline Busy & 26 & $25.2 \%$ \\
\hline Culture & 22 & $21.4 \%$ \\
\hline $\begin{array}{l}\text { Don't know the } \\
\text { importance }\end{array}$ & 22 & $21.4 \%$ \\
\hline Environment & 7 & $6.8 \%$ \\
\hline Feeling shy & 10 & $9.7 \%$ \\
\hline Total & 103 & $100.0 \%$ \\
\hline
\end{tabular}

Being busy [25.2\%] was the major reason for poor male involvement in PMTCT programs.

\section{DISCUSSION}

The results show that among 138 respondents,103(74.6\%) were not willing to participate in PMTCT programs by accompanying their couples to the Antenatal Clinics. These findings are nearly similar to those of Tshibumbu.D.D in 2006 in Zambia who pointed out that PMTCT programs have largely focused on encouraging women to come for the PMTCT services but have often left out men's as critical decision makers and if men are not knowledgeable of the benefits of the PMTCT and clearly understand the risks to their children, they will not give a supportive force for PMTCT uptake and compliance. ${ }^{7}$

In Hedaru, majority of the respondent (61.6\%) had never accompanied their couples to the ANC. This probably could contribute to the knowledge deficit to the majority of males simply because PMTCT information and services are most likely to be found at ANC rather than somewhere else. This was supported by the study done by Munene E.M (2004) in Uganda, which reported that men felt that it's not necessary to accompany their spouses for ANC and majority of the males responded that "I would only go there to drop my wife on a bicycle or I give her money for taxi, why should I go with her". 8

Regarding the reasons why most men are not involved in PMCTC programs, 26(25.2\%) said that they were busy with daily activities so that they could not manage to accompany their spouses to the ANC as the clinics are mostly opened during the day time when majority of them are in their various working centres. This finding is almost similar to the study done by Kunene in 2004 in South Africa, with the broad strategies of improving antenatal care services by strengthening the existing antenatal packages and introducing couple counselling by inviting partners of antenatal women to attend counselling twice during pregnancy and one post delivery. He found that some men expressed willingness to attend , but were unable to do so due to employment schedules that conflicted with clinic hours of operation, and inability to obtain permission from employers. ${ }^{9}$

About 16(15.5\%) perceived ANC services as women affairs. They said women are responsible for care of the pregnancy and delivery of the baby. In fact this have contributed to knowledge deficit and poor participation of males in PMTCT services as it is supported by the study done in Tanzania at Majengo $\mathrm{MCH}$ clinic in Moshi municipality to describe the reasons for failure to participate in PMTCT services. Among the reasons given in the study was the perception that pregnancy and child issues are women's arena.

Others (21.4\%) were not supported by culture in their community and $9.7 \%$ said they feel shy. This could be the reason why males are lagging behind on PMTCT services as most of the time, responsibilities were left for females only. This correlates with the study done by Horizon program (2002) in Zimbabwe that reported that, communities considered the man who publicly supported his wife by accompanying her to the clinic as weak or bewitched. ${ }^{10}$

Also $6.8 \%$ of the respondents said that ANC were not supportive to them in the sense that, presence of the males at ANC was not recognized and respected by the health professionals as well as pregnant women attending the clinic. Also most of the workers at ANC clinics are female nurses from which males fill difficult to access information on reproductive health. Probably this could also contribute to the disparity of the knowledge to the males as they were not well motivated to attend ANC where information on PMTCT is easily accessed. This is supported by the study done by Path program which reported that, antenatal, mother and child health clinics are women's spaces that cannot be easily adapted to accommodate men. ${ }^{11}$

Among those who participated in PMTCT services, only 48.6\% were searching for health education like HIV/ 
AIDS in pregnancy, and family planning education; the reasons which are relevant to ANC responsibility. The other $42.9 \%$ participated so that they can show true love to their wives/partner and $8.5 \%$ was due to great distance from their settlements to the ANC centres; the reasons which are not relevant with ANC responsibilities. These findings show that men lack knowledge about the importance of their participation in PMTCT services when compared with the above reasons.

\section{CONCLUSION}

Most males do not participate in PMTCT programs because they don't realise their importance due to inadequate knowledge about the programs, while others are hindered by cultural settings in the community which pose negative perceptions toward the programs.

\section{RECOMMENDATIONS}

PMTCT clinics should be made male friendly and service providers should ensure that all efforts are made to involve male from the beginning in every PMTCT intervention. Men should be enforced to accompany their couples to the ANC through denying maternal services to the mother unless she comes with her husband/partner.

\section{REFERENCES}

1. Ministry of health PMTCT Manual; Tanzania, (2004).

2. UNAIDS. End-2004 global HIV and AIDS estimates, www.unaids.org 2005.

3. Ladner J, Leroy V, Msellati P, Nyiraziraje M, De CA, Van de PP, Dabis F, factors associated with failure to return for HIV post-test counselling in pregnant women: Deqrees du lou, vol 11(61-87)

4. Ekouevei et al uptake of PMTCT interventions among HIV infected pregnant women, SSM vol.69 no.6(892899).

5. Bajunirwe F and Muzoora M, Barriers to the implementation of programs for the prevention Of maternal to child transmission of HIV : Uganda. Mbarara Uganda 2005

6. Kisanga B, Fimbo J, Murutu H,Simboni A,Msuya A,Kimaro $M$, et al, The involvement of men in prevention of PMTCT of HIV PROGRAM at primary health centre", Moshi urban: prevalence and perceived barriers,(2004).

7. Tshibumbu .D.D, Factors influencing men's involvement in prevention of mother to child transmission (PMTCT) of HIV programmes, MPH-USA(november 2006).

8. Gathenya G. and Munene .E.M. Mobilizing male support in prevention mother to child transmission of HIV (PMTCT), 2004-XV-AIDS International conference.

9. Kunene B,Beksinnska M,Zond S, MTHEMBU N,Mullick S,Ottolegh, involving Men in maternity care, october 2004.

10. Dadian MJ, Integrating HIV Prevention and care into maternal and child health care setting, GlobalAIDSlink, 2002,vol.73:.5,16.

11. Program for appropriate Technology in Health(PATH), Involving men in reproductive health, 1997, vol.14, (3). 